\title{
MAPPING GROUNDWATER AREAS
}

\author{
Tuire Valli and Annina Mattsson \\ Geological Survey of Finland
}

\section{INTRODUCTION}

The volume of environmental research has increased in the Geological Survey of Finland (GTK) during the 1990's. The surveys of groundwater areas have played a remarkable role in them, because of the municipal needs for groundwater. The growing risk of pollution, environmental accidents etc. requires information about the flow and storage capacity of groundwater. Geophysical methods have turned out to be a useful tool in giving regional information of bedrock topography and the thickness of overburden. In these studies GTK has worked as a consult and contractor for cities, municipalities and regional environment centers.

\section{METHODOLOGY}

A typical groundwater area in Finland consists of a sandy esker (or end moraine) underlaid by more or less fractured bedrock. The survey of this kind of groundwater area begins with regional methods and continues with more detailed measurements. A typical survey consists of five phases as follows:

(1) Location of fractured zones

At first, the bedrock structure is interpretated regionally; the fractured zones and faults are located by using topographic and airborne geophysical data.

The digital elevation model is produced by National Land Survey of Finland. The grid size is 25 $\mathrm{m}$ and the elevation indication is in decimeters. The data generally shows the greatest fractures of bedrock and shows the continuity of them.

In Finland the second aerogeophysical mapping program has been carried out since 1972. The flight altitude is $30-40$ metres, spacing of flight lines $200 \mathrm{~m}$ and the sampling interval $12 \mathrm{~m}$. The magnetic field is measured with two wingtip magnetometers. In the AEM measurements vertical coplanar coil configuration is used. The coil separation is $21.4 \mathrm{~m}$ and the frequencies $3112 \mathrm{~Hz}$ and $14368 \mathrm{~Hz}$ (see Lerssi et.al., this issue). Earths gamma radiation is measured with a spectrometer having a 25 -litre NaI-crystal detector unit. Atmospheric radiation is reduced with upward looking crystals. The sampling interval in radiometric measurements is $50 \mathrm{~m}$. The mapping progresses by about $13,000 \mathrm{~km}^{2}$ per year, and currently more than $80 \%$ of Finland's area has been mapped. The aerogeophysical data is easy to manipulate into different kinds of 
forms.

The main method in interpretating fractured zones is to analyse the aeromagnetic maps. The fractured zones and faults can be seen as magnetic minima because the magnetic minerals have oxidized in the fractured water-bearing zones. Airborne magnetic data has sometimes used also to interpret the thickness of overburden.

Fractured zones cause recognisable AEM anomalies if the overburden on the fracture is thicker than in the surroundings. In a wet environment, such as clay and peat, the resistive till and sand areas are shown as local minima.

The radiometric data has mainly been used to detect bedrock terrain where the overburden is less than $1 \mathrm{~m}$. The radiation weakens in watercourse and in wetlands and produces a minimum on a radiometric map. These wet overburden areas can sometimes discharge groundwater.

(2) Estimating the thickness of overburden with gravimetric method

In large groundwater areas the gravity profile measurements are essentially useful to estimate the thickness of overburden. The glasifluvial formations are often a few kilometres wide and the thickness of the formations can be even 50 to 100 metres. The gravimetric effects of thick overburden varies about -2 to $-4 \mathrm{mGal}$. In-situ density typically ranges from $1400-1600 \mathrm{~km} / \mathrm{m}^{3}$ for dry and fine-grained material to $2000-2400 \mathrm{~kg} / \mathrm{m}^{3}$ for wet and coarse-grained material (Elo, 1995). For determining the regional variation of gravity, the profiles must begin and end on an bedrock outcrop or on a point where the thickness of overburden is known. The measurement lines are usually designed also to cross each other for getting more confident interpretation.

These methods are used in two ways: to interpret the thickness of overburden and to classify various topographic features with estimating in-situ surface densities using Nettleton's method. The mean density obtained can also be used when interpreting the bedrock topography.

(3) Ensuring the gravimetric interpretation with other methods

After estimating the thickness of overburden, the study continues with seismic refraction and GPR soundings and overburden drillings at selected profiles and points. These measurements improve the preliminary interpretation of the bedrock topography and groundwater level. They also help to estimate the in-situ overburden densities.

\section{(4) Final interpretation of gravity measurements}

When all information is available, the second gravimetric interpretation can be made. By using the seismic and GPR results and the groundwater level data (in springs and in observation wells), the thickness of overburden can be estimated considerably reliably by gravimetric interpretation. It is especially important to know the correct groundwater level, because the density of wet overburden is much higher than the uppermost dry layer. If the bedrock density varies a lot in the investigation area, it is difficult to get detailed information of the soil thickness. However, the results of gravimetric and seismic interpretation together with drilling information helps to estimate the topography of bedrock fairly well. 
By merging all available data, the hydrogeological conclusions can be made. The data usually consists of geological and geophysical interpretations, geological maps and information from observation wells and overburden drillings. With the knowledge achieved, a three-dimensional model of the groundwater area is produced and the most suitable areas for groundwater utilization and artificial recharge can be pointed out.

\section{THE VEHONIEMI CASE}

GTK mapped in cooperation with the Tampere-district water-support project (TAVASE) the structure and groundwater conditions of an Eaker area in western Finland. The purpose of the investigation was to determine the thickness of overburden and the locations of the possible discontinuities of the bedrock topography.

The investigation started with regional interpretation of bedrock structure. The topographic, aerogeophysical and geological maps were studied, and the fractured zones and faults were defined, and after that the gravity profiles were planned in suitable places.

In the second phase, the gravimetric profile-measurements were carried out. The mean density of overburden was estimated by Nettleton's method in order to find out if the local maximum of the topographical shape was caused by bedrock or soil. In the esker area there was very little knowledge of the overburden, and the gravimetric interpretation was based on the assumption that the regional anomaly was as low as possible. This confirmed that the interpretated thicknesses were not too great.

Next, the adjusting methods were planned in the Eaker area. The thickness of overburden in certain places, the groundwater level and the topography of bedrock was defined by seismic refraction method. Some GPR profiles were also measured in order to find out the internal structure of overburden. Complementary gravimetric profiles were measured and preliminary interpretation was made to specify the suitable points for overburden drilling.

By using all the available data, the gravimetric profiles could be interpretated again. The bedrock and overburden densities varied very much in this area, which caused a lot of problems in interpretation. The regional anomaly could be placed in correct level after having enough knowledge of the density and the depth of bedrock and of groundwater level. The results of the second interpretation phase showed the overburden to be much thicker than the thicknesses interpretated in the first phase.

Finally, the 3-D model of the Eaker area was complied. The results showed that the overburden at Vehoniemi area was exceptionally thick, in many places $60-80$ metres and thus the storage capacity of groundwater was also large.

\section{DISCUSSION AND CONCLUSIONS}

The comparison of the different methods emphasizes the importance of the two-phase interpretation of gravimetric profiles. In the first phase, it is possible to obtain information about the topography of bedrock and the drilling points can be directed. After having more data of the 
depth and density of the bedrock, the second interpretation can be performed, and more reliable results will be obtained.

The advantage of this methodology is; with regional interpretation the more detailed and more expensive investigations can be located to the most promising areas and thus reduce the costs of the investigation. Further, the best areas for groundwater utilization can be chosen.

The information achieved can also be used in many other contexts, like in studying contaminated areas. The groundwater carries the pollutants and therefore it is important to know the water flows. Another application for these studies is in city planning, where building requires regional knowledge of soil thicknesses and types.

The need of this kind of studies has increased year after year. Last year the mapping of groundwater areas was the most significant target of ground geophysical studies in the southern regional office of GTK.

\section{REFERENCES}

ELO, S., 1995. Gravity anomalies due to overburden, bedrock weathering and fracture zones. 57th EAEG meeting, Extended Abstracts, p. 141.

MATTSSON, A., 1996. Mapping eskers with geophysical methods - locating the most suitable areas for groundwater utilization. 2nd EEGS Meeting, Nantes, Proceedings, 55 - 57.

MATTSSON, A., 1996. Mapping Groundwater Areas with Geophysical Methods. Proceedings of the Symposium on the Application of Geophysics to Engineering and Environmental problems, SAGEEP'96, 997 - 1005.

LEHTIMÄKI, J., 1995. Seismic soundings at Vehoniemi esker, Kangasala, 1995. Report, Geological Survey of Finland, pp. $4+9$ (in Finnish).

LEHTMMÄKI, J., 1996. Geophysical studies at Vehoniemi esker, Kangasala, 1994 - 1996. Report, Geological Survey of Finland, pp. $5+15$ (in Finnish). .

LERSSI, J., KURIMO, M., JOKINEN, T., AND PURANEN, R., 1997: Airborne geophysics for environmental studies in Finland. This issue.

PALMU, J-P., VALLI, T., 1995. Gravimetric studies at Pälkäne, Isokangas and Vehoniemi Kangasala. Report, Geological Survey of Finland, pp. $8+6 \mathrm{~s}$. 